\title{
The effect of camelina oil ( $\alpha$-linolenic acid) and canola oil (oleic acid) on lipid profile, blood pressure, and anthropometric parameters in postmenopausal women
}

\author{
Małgorzata A. Dobrzyńska, Juliusz Przysławski
}

Department of Bromatology, Poznan University of Medical Sciences, Poznan, Poland

Submitted: 25 September 2018; Accepted: 3 December 2018

Online publication: 31 March 2020

Arch Med Sci 2021; 17 (6): 1566-1574

DOI: https://doi.org/10.5114/aoms.2020.94033

Copyright @ 2020 Termedia \& Banach

\section{Abstract}

Introduction: Cold-pressed camelina oil (Camelina sativa) is rich in polyunsaturated fatty acids and may have a beneficial effect on the reduction of cardiovascular risk.

Material and methods: In this study, we investigated the parameters contributing to the development of cardiovascular diseases, such as dietary intake, nutritional status, blood pressure, and lipid profile. Sixty postmenopausal women with dyslipidaemia were randomly assigned to two oil groups: camelina oil and canola oil. The subjects consumed daily $30 \mathrm{~g}$ of the test oils for 6 weeks. Before and after dietary intervention, the assessment of nutrition (4-day dietary recall), anthropometric parameters, lipid profile, and blood pressure were evaluated.

Results: During the dietary intervention, decreased low-density lipoprotein cholesterol concentration in both groups $(15 \mathrm{mg} / \mathrm{dl}(0.4 \mathrm{mmol} / \mathrm{l})$ reduction in the camelina oil group and $11 \mathrm{mg} / \mathrm{dl}(0.3 \mathrm{mmol} / \mathrm{l})$ reduction in the canola oil group) was observed. In this study a decrease of waist circumference (approx. $1 \mathrm{~cm}$ ) in the two groups was observed. In the group of women consuming camelina oil, a significant decrease of waist-to-hip ratio was seen. In the other anthropometric parameters no statistically significant changes were observed (body weight, body fat mass). After the intervention, no significant decreases in systolic and diastolic blood pressure were noticed.

Conclusions: The camelina and canola oil intake contributed to reduction of the consumption of saturated fatty acids in the diet, had a positive influence on the lipid profile parameters, and decreased the waist circumference, which may reduce the risk of cardiovascular disease.

Key words: cardiovascular disease, lipid profile, dyslipidaemia, canola oil, camelina oil.

\section{Introduction}

Cardiovascular disease is the foremost cause of death in the world. There are many factors associated with increase of cardiovascular risk, such as increased serum cholesterol concentration, increased serum low-density lipoprotein (LDL) cholesterol concentration, hypertension, low physical activity, incorrect eating behaviour, and some clinical disorders or socio-economic factors [1-4]. In addition, nowadays attention is paid to genetic factors predisposing to cardiovascular disease [5].

\author{
Corresponding author: \\ Matgorzata A. Dobrzynska \\ $\mathrm{PhD}$ \\ Department of Bromatology \\ Poznan University \\ of Medical Sciences \\ 42 Marcelińska St \\ 60-354 Poznan, Poland \\ E-mail: mdobrzynska@ump. \\ edu.pl
}


The association between the higher risk of cardiovascular disease and dyslipidaemia in postmenopausal women was observed in a lot of studies. It is widely known that diet intervention plays a significant role in reducing the cardiovascular risk factors such as body weight and lipid profile $[1,6,7]$.

A study on the relationship between diet and cardiovascular disease was initiated by Keys et al. research [8]. It has a high intake of saturated fatty acid (SFA) and cholesterol while reducing the polyunsaturated fatty acid (PUFA) intake, which contributes to an increase in serum cholesterol. Further studies on PUFA showed that linoleic acid (LA) and $\alpha$-linolenic acid (ALA) compete for the enzymatic plasma membrane [9]. Consequently, a high LA diet may reduce the content of ALA $[10,11]$. Another dietary pattern indicating a beneficial influence on cardiovascular disease is the Mediterranean diet, which is rich in oleic acid from olive oil. Research in this field over the past years has showed health benefits associated more with whole Mediterranean diet and less with isolated nutrients [12, 13]. Subsequently, research has focused on n-3 fatty acid, especially eicosapentaenoic acid, docosahexaenoic acid, and ALA acid. The studies were concentrated on readily available vegetable oils. A good example turned out to be linseed oil, which has a high content of ALA (52-60\%) and LA (15-17\%) and low content of SFA (9-11\%) [14]. Unfortunately, the high PUFA content of this oil contributes to its rapid oxidation [15]. Currently, a good source of PUFA is sought with a favourable ratio of $n-3$ to $n-6$, which would have a cardioprotective effect.

Therefore, a study was undertaken to determine the effect of camelina oil rich in PUFA with favourable proportions of $n-3$ to $n-6$ and rich in monounsaturated fatty acids (MUFA).

It is worth noting that canola oil in this study was used like a reference point (placebo). This research assumption was due to the fact that the studied group (Polish population) use this oil in their usual daily diet. The effect on lipid profile parameters and anthropometric parameters regarding the reduction of cardiovascular risk was evaluated.

\section{Material and methods}

The study included a group of 60 postmenopausal women (aged 45-65 years) with dyslipidaemia. The inclusion criteria in the study were: serum total cholesterol concentration above $190 \mathrm{mg} / \mathrm{dl}$ (approx. $5.0 \mathrm{mmol} / \mathrm{l}$ ), menopause (absence of menstrual period for at least 12 months), and non-admission lipid-lowering medication. Exclusion criteria were: hormone replacement therapy, diabetes, cancer, liver, kidney, thyroid or acute coronary disease, previous coronary artery bypass surgery, previous stroke, myocardial infarction, alcohol use more than $10 \mathrm{~g}$ ethanol per day, eating disorders such as anorexia and bulimia, and other difficulties in exchanging dietary fat to test oils.

According to the interview, the women participating in the study were characterised by low physical activity (physical activity level (PAL) $=1.4$ ). Eight per cent of the examined women smoked cigarettes (two consuming camelina oil and three consuming canola oil).

Subjects were asked not to change their dietary habits, physical activity, or the use of stimulants throughout the study.

It is worth noting that each of the women was informed about the purpose of research, anonymity, voluntary participation, and the possibility of resignation at any stage without having to give a reason. Patients expressing willingness to participate in the study and fulfilling its criteria signed statements including consent to taking blood twice, adhering to dietary recommendations, and keeping nutritional notes from the course of research. The women kept a so-called "diary of consumption", informing the researcher about the amount of oil consumed, the hour of its consumption, and possible side effects. In addition, the participants were under constant control of the dietician throughout the whole period of research. Meetings with patients were individual (face to face) and provided direct and unhampered contact.

The course of the dietary intervention. The trial followed a randomised, double-blind, six-week intervention. Women were recruited through newspaper ads and posters. The patients were recruited by a specialised dietician. Women fulfilling the test criteria were divided into two groups. The first group of women consumed $30 \mathrm{~g}$ of cold-pressed camelina oil during the day $(n=30)$ and the second group - $30 \mathrm{~g}$ cold-pressed canola oil $(n=30)$, in exchange for $30 \mathrm{~g}$ of fat used by them in their daily diet, including the same energy value of the diet. The permission of the Bioethics Committee of Poznan University of Medical Sciences - Resolution No. 561/13 of June 13, 2013, was obtained to conduct the research.

Patients consumed the test oil three times a day (for breakfast, lunch, and dinner in the amount of $10 \mathrm{~g}$ ). Some patients consumed the oil twice a day - $15 \mathrm{~g}$ (for breakfast and dinner), which was related to the specificity of the diet of patients. During the dietary intervention, women did not change their eating habits. The examined women measured the amount of oil consumed with the use of a medical measuring cup and were asked to record the quantities consumed in their nutritional diary. The oils were delivered to pa- 
Table I. Composition of selected groups of fatty acids in test oils (\%)

\begin{tabular}{|c|c|c|}
\hline Variable & Camelina oil & Canola oil \\
\hline Saturated fatty acids & 10.3 & 7.6 \\
\hline Monosaturated fatty acids & 33.8 & 61.6 \\
\hline Polyunsaturated fatty acids & 55.8 & 30.2 \\
\hline$n-3$ & 33.2 & 9.5 \\
\hline$n-6$ & 22.1 & 21.7 \\
\hline$n-9$ & 30.3 & 59.1 \\
\hline$\alpha$-linolenic acid & 35.3 & 12.7 \\
\hline Linoleic acid & 16.9 & 17.5 \\
\hline Oleic acid & 16 & 57.9 \\
\hline
\end{tabular}

tients in $200 \mathrm{ml}$ dark glass bottles without labels, making it impossible to recognise the oil. The dietician during the visits controlled the amount of oil consumed. Table I presents the composition of the tested vegetable oils - a group of fatty acids, determined by means of gas chromatography (HP 6890 Series from Hewlett Packard) equipped with a flame ionisation detector (FID) and split/splitless inlet. A $60 \mathrm{~m} \times 0.32 \mathrm{~mm}$ i.d., $0.25 \mu \mathrm{m}$, capillary column BPX 70 was used. The carrier gas was helium, with a flow rate of $1.5 \mathrm{~cm}^{3} / \mathrm{min}$, and variable temperature programming was used.

In the studied groups of women, before and after the dietary intervention, the following factors were evaluated: dietary intake, basic anthropometric measurements, blood pressure, and lipid profile in blood serum.

The anthropometric measurements including body weight, height, and waist and hip circumferences were measured. Weight and height were determined with subjects in underwear using a SECA scale (measurement precision $0.1 \mathrm{~cm}$ ). The measurements were taken according to the current recommendations [16]. Waist circumference was measured at the narrowest level between the costal margin and iliac crest, and the hip circumference was measured at the widest level over the buttocks while the subjects were standing normally. Body mass index (BMI) was calculated by dividing body mass $(\mathrm{kg})$ by height (m) squared and waist-to-hip ratio (WHR) as the proportion of waist to hip circumferences [17]. The body fat mass (FM) was assessed by the bioimpedance method using a Tanita Body Fat Analyzer (model - BC 420 S MA with a medical certificate).

The assessment of nutrition was evaluated via 24-hour dietary recall during 4 days (including 1 day off work) according to the guidelines elaborated by the National Institute of Food and Nutri- tion [18]. Each of the women was trained in the proper completion of the questionnaire. The subjects gave the type of food products with the determination of their measures and hours of consumption. In order to determine the amount of food consumed, a "Photo album of products and dishes" published by the Institute of Food and Nutrition was used [19]. The obtained results made it possible to calculate the energy and nutritional value of all-day food rations. To analyse the qualitative and quantitative composition of the diet, relational databases developed in Microsoft Access 2010 were used [20]. The calculations include the loss of vitamins during culinary and technological processes, amounting to vitamins: A $-25 \%$, B1 - 20\%, B2 - 15\%, B6 - 20\%, C - 55\%, E - 20\%, folacin $-80 \%$, and PP $-20 \%$ [21]. The food intake recommendations of the Institute of Food and $\mathrm{Nu}$ trition were taken into consideration to determine the degree to which the Recommended Dietary Allowances were met [22]. A low level of physical activity was assumed - according to the declaration from the women participating in the study.

At each period, blood pressure was measured in the left arm by an examining researcher using a mercury column sphygmomanometer after the subject had been at rest in the seated position for $\geq 15$ min.

Biochemical tests were performed in the Central Laboratory of Gynaecology and Obstetrics of the Clinical Hospital of Poznan University of Medical Sciences, and they included determination of lipid profile parameters (total cholesterol concentration and its fraction, triglyceride concentration) in blood serum.

\section{Statistical analysis}

The data was analysed using the statistical program Statistica (StatSoft, Inc. 2015) (data analysis software system), version 12.5 . First, basic descriptive statistics were used, specifying: mean (x), standard deviation (SD), and median (Me).

The normality of the distribution was assessed using the Shapiro-Wilk test. Analysing the differences between variables within two groups (for independent variables), for the normal distribution and equal variances, Student's $t$-test for two independent groups was used, while for the normal distribution and for different variances, the Cochran-Cox test was used. In the absence of normality, the Mann-Whitney $U$ test was used.

Analysing the differences between variables within the same group (analysis for dependent variables), Student's $t$-test for two dependent groups was used for normal distribution and equal variances. In the absence of normality, the Wilcoxon signed-rank test was used. 
To estimate the possible influence of additional factors (age, BMI) on the change in lipid profile parameters, in this study we used Spearman rank correlation (in the absence of normality) and Pearson correlation (for the normal distribution). Analysing the possible influence of smoking, we used Student's $t$-test for two independent groups (for the normal distribution) and the Mann-Whitney $U$ test (in the absence of normality).

In the data analyses carried out, $\alpha=0.05$ was assumed as the materiality level.

\section{Results}

Before the beginning of the dietary intervention, no statistically significant differences were found between the groups in the values of anthropometric parameters, i.e. body weight, waist circumference, hip circumference, BMI, and WHR (Table II). During the run-in period, there was a significant decrease in waist circumference in both groups, and WHR value in the camelina group. In other anthropometric parameters, no statistically significant differences were observed.
Compliance with the use of test products was good, and there were no differences between the test groups. The average total amount of the test oil was $29.6 \pm 1.6 \mathrm{~g} / \mathrm{d}$ in the group of women consuming cold-pressed camelina oil and $29.3 \pm 2.8 \mathrm{~g} / \mathrm{d}$ in the group of cold-pressed women canola oil. During the intervention, the test oils replaced mostly butter used for spreading on bread and rapeseed oil used for thermal processing. In the remaining patients, the shortening fat derived from sweet snacks or animal fat from meat was replaced.

According to the assumptions of the study, as a result of a dietary intervention, no statistically significant differences were found between the energy value and fat content in all-day food rations in the studied groups of women. Dietary intake of energy and nutrients during the pretrial and intervention periods are presented in Table III. There were no differences in the diet among the test groups during the pretrial period. As predicted, the intake of PUFA was significantly higher in the camelina oil group compared to the canola oil group $(p<0.05)$. Simultaneously, the intake of

Table II. Characteristic of study subject

\begin{tabular}{|c|c|c|c|c|c|c|c|}
\hline \multirow[t]{2}{*}{ Parameter } & \multicolumn{2}{|c|}{ Camelina oil } & \multirow[t]{2}{*}{$P$-value } & \multicolumn{3}{|c|}{ Canola oil } & \multirow[t]{2}{*}{$P$-value* } \\
\hline & $\begin{array}{c}\text { Pretrial } \\
\text { period } \\
(n=30)\end{array}$ & $\begin{array}{l}\text { After in- } \\
\text { tervention } \\
(n=30)\end{array}$ & & $\begin{array}{l}\text { Pretrial } \\
\text { period } \\
(n=30)\end{array}$ & $\begin{array}{c}\text { After } \\
\text { interven- } \\
\text { tion } \\
(n=30)\end{array}$ & $P$-value & \\
\hline Age [years] & \multicolumn{2}{|c|}{$55 \pm 5$} & \multicolumn{4}{|c|}{$57 \pm 4$} & \\
\hline Weight [kg] & $71.4 \pm 15.6$ & $71.2 \pm 15.0$ & $0.9713^{*}$ & $70.0 \pm 16.5$ & $69.9 \pm 16.0$ & $0.5481^{*}$ & \\
\hline Height $[\mathrm{cm}]$ & \multicolumn{2}{|c|}{$163 \pm 5$} & \multicolumn{4}{|c|}{$161 \pm 5$} & \\
\hline $\mathrm{BMI}\left[\mathrm{kg} / \mathrm{m}^{2}\right]$ & $26.7 \pm 5.3$ & $26.7 \pm 5.04$ & $0.8664^{*}$ & $26.9 \pm 6.4$ & $26.8 \pm 6.17$ & $0.5481^{*}$ & \\
\hline Waist circumference $[\mathrm{cm}]$ & $91.2 \pm 14.9$ & $90.2 \pm 14.1$ & $0.0049^{*}$ & $89.6 \pm 13.2$ & $88.9 \pm 13.0$ & $0.0158^{*}$ & \\
\hline Hip circumference $[\mathrm{cm}]$ & $102 \pm 11$ & $102 \pm 10.6$ & $0.4755^{\star}$ & $102 \pm 13$ & $102 \pm 13.5$ & $0.0995^{\star}$ & \\
\hline WHR & $0.89 \pm 0.06$ & $0.88 \pm 0.6$ & $0.0166^{* *}$ & $0.87 \pm 0.04$ & $0.87 \pm 0.5$ & $0.1102^{* \star}$ & \\
\hline FM (\%) & $35.6 \pm 7.2$ & $35.5 \pm 6.71$ & $0.5146^{\star \star}$ & $36.1 \pm 6.38$ & $36.9 \pm 7.2$ & $0.8287^{*}$ & \\
\hline $\begin{array}{l}\text { Systolic blood pressure } \\
{[\mathrm{mm} \mathrm{Hg}]}\end{array}$ & $131 \pm 15$ & $129 \pm 12$ & $0.2907^{* *}$ & $126 \pm 13$ & $125 \pm 14$ & $0.6498^{*}$ & \\
\hline $\begin{array}{l}\text { Diastolic blood pressure } \\
{[\mathrm{mm} \mathrm{Hg}]}\end{array}$ & $79 \pm 11$ & $77 \pm 9$ & $0.1969^{*}$ & $78 \pm 7$ & $75 \pm 7$ & $0.9018^{* *}$ & \\
\hline $\mathrm{TC}[\mathrm{mg} / \mathrm{dl}]$ & $242 \pm 34.1$ & $223 \pm 37.8$ & $0.0002^{*}$ & $239 \pm 32.8$ & $225 \pm 36.3$ & $0.0055^{* \star}$ & $0.3952^{\circ}$ \\
\hline LDL-C [mg/dl] & $147 \pm 32.1$ & $132 \pm 35.0$ & $<0.00001^{\star *}$ & $146 \pm 35.8$ & $135 \pm 39.6$ & $0.0050^{\star *}$ & $0.3606^{\circ}$ \\
\hline $\mathrm{HDL}-\mathrm{C}[\mathrm{mg} / \mathrm{dl}]$ & $69.4 \pm 15.2$ & $68.1 \pm 14.2$ & $0.2805^{* *}$ & $71.8 \pm 19.4$ & $72.0 \pm 19.3$ & $0.7071^{*}$ & $0.5493{ }^{\circ}$ \\
\hline $\mathrm{TG}[\mathrm{mg} / \mathrm{dl}]$ & $125 \pm 77.8$ & $116 \pm 53.8$ & $0.4427^{*}$ & $105 \pm 41.6$ & $93.9 \pm 32.0$ & $0.0472^{*}$ & $0.6204^{\star \star \star}$ \\
\hline Non-HDL-C [mg/dl] & $173 \pm 36.4$ & $155 \pm 37$ & $0.0001^{* *}$ & $167 \pm 37.6$ & $153 \pm 43.6$ & $0.0043^{* *}$ & $0.5456^{\circ}$ \\
\hline
\end{tabular}


Table III. Energy and selected nutrient composition of diet before and during the intervention

\begin{tabular}{|lcccc|}
\hline Parameter & $\begin{array}{c}\text { Pretrial period } \\
(n=60)\end{array}$ & $\begin{array}{c}\text { Camelina oil } \\
(n=30)\end{array}$ & $\begin{array}{c}\text { Canola oil } \\
(n=30)\end{array}$ & $P_{\text {-value* }}^{*}$ \\
\hline Energy [kcal/day] & $2157 \pm 401$ & $2144 \pm 401$ & $2170 \pm 416$ & $0.5298^{* * *}$ \\
\hline Fat (E \%) & $39.1 \pm 5.3$ & $39.0 \pm 5.8$ & $39.1 \pm 4.9$ & $0.7747^{* * *}$ \\
\hline Saturated fatty acids (E \%) & $12.5 \pm 3.6$ & $13.2 \pm 4.0$ & $11.9 \pm 2.9$ & $0.4142^{*}$ \\
\hline Monosaturated fatty acids (E \%) & $15.5 \pm 2.6$ & $15.4 \pm 2.9$ & $15.5 \pm 2.4$ & $0.0001^{* *}$ \\
\hline Polyunsaturated fatty acids (E \%) & $7.6 \pm 2.8$ & $6.9 \pm 2.0$ & $8.3 \pm 3.3$ & $0.0067^{* * *}$ \\
\hline Protein (E \%) & $15.4 \pm 2.3$ & $15.3 \pm 2.3$ & $15.5 \pm 2.4$ & $0.8349^{*}$ \\
\hline Carbohydrates (E \%) & $49.2 \pm 6.1$ & $49.3 \pm 6.6$ & $49.0 \pm 5.7$ & $0.9357^{*}$ \\
\hline Fibre [g/day] & $24.0 \pm 7.6$ & $25.6 \pm 6.5$ & $25.2 \pm 8.1$ & $0.8086^{*}$ \\
\hline Cholesterol [mg/day] & $461.2 \pm 218.7$ & $353.6 \pm 141.5$ & $357.1 \pm 198.5$ & $0.6843^{* * *}$ \\
\hline
\end{tabular}

"'Mann-Whitney U test, 'Student's t-test for two independent groups, “'Cochran-Cox test, E \% - percentage of energy.

MUFA was significantly higher in the canola oil group compared to the camelina oil group. The differences in the dietary intake among the groups were related to the fatty acid composition of the test oils.

Dietary intervention contributed to the change in the percentage of energy from SFA, MUFA, PUFA, and essential fatty acids (EPA). In the case of women consuming camelina oil, a decrease in the percentage of energy from SFA by $3.8 \%$ and a reduction in the percentage of energy from MUFA by $0.8 \%$ was observed. Regarding the percentage of energy from PUFA, an increase of $6 \%$ was observed. In women whose all-day food rations contained canola oil, the percentage of energy from SFA decreased by $3 \%$, from MUFA it increased by $2.2 \%$, and in the case of PUFA it increased by $2.4 \%$. In the case of the percentage of energy from EPA in all-day food rations, women consuming

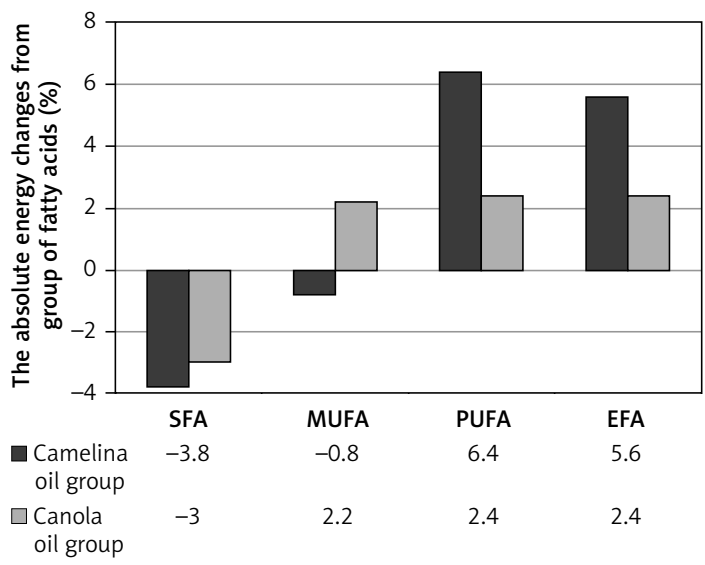

Figure 1. Changes in the energy (\%) from SFA, MUFA, PUFA, and EFA in the diet during the dietary intervention

SFA - saturated fatty acids, MUFA - monounsaturated fatty acids, PUFA - polyunsaturated fatty acids, EFA - essential fatty acids camelina oil increased their percentage by $5.6 \%$, and in the group of women consuming canola oil it increased by $2.4 \%$. Except for the percentage of energy from MUFA in women consuming camelina oil, statistically significant differences were found in all groups of fatty acids.

The difference between the studied groups in the percentage of energy from SFA was higher by less than $0.8 \%$ in the group of women consuming camelina oil. In the case of the energy percentage from MUFA, this difference was higher by $3 \%$ in the group of women consuming canola oil. The most significant difference between the groups was observed in the percentage of energy from PUFA, which was 3.6\% (Figure 1).

During the intervention there were no significant changes in blood pressure (systolic and diastolic) within the test groups (Table II).

The lipid profile of the studied groups of women before and after nutritional intervention (camelina oil vs. canola oil) is presented in Table II. During the intervention serum total cholesterol (TC) decreased from $242 \mathrm{mg} / \mathrm{dl}(6.3 \mathrm{mmol} / \mathrm{l})$ to $223 \mathrm{mg} /$ $\mathrm{dl}(5.8 \mathrm{mmol} / \mathrm{l})$ in the group of women taking camelina oil, and from $239 \mathrm{mg} / \mathrm{dl}(6.2 \mathrm{mmol} / \mathrm{l})$ to $225 \mathrm{mg} / \mathrm{dl}(5.8 \mathrm{mmol} / \mathrm{l})$ in the group of women taking canola oil. The serum LDL cholesterol decreased from $147 \mathrm{mg} / \mathrm{dl}(3.8 \mathrm{mmol} / \mathrm{l})$ to $132 \mathrm{mg} / \mathrm{dl}$ $(3.4 \mathrm{mmol} / \mathrm{l})$ in the camelina oil group, and $146 \mathrm{mg} / \mathrm{dl}$ $(3.8 \mathrm{mmol} / \mathrm{l})$ to $135 \mathrm{mg} / \mathrm{dl}(3.5 \mathrm{mmol} / \mathrm{l})$ in the canola oil group. There were no significant changes in serum high-density lipoprotein (HDL) cholesterol concentration within the test groups. Interestingly, the concentration of serum triglycerides (TG) significantly decreased only in the canola oil group, from $105 \mathrm{mg} / \mathrm{dl}(1.2 \mathrm{mmol} / \mathrm{l})$ to $93 \mathrm{mg} / \mathrm{dl}(1.1 \mathrm{mmol} / \mathrm{l})$. Dietary intervention contributed to decreased non$\mathrm{HDL}$ cholesterol concentration in both groups.

It is worth pointing out that the analysis of the possible influence of additional factors (age, BMI 
Table IV. The age, BMI value, and smoking status and their influence on the change in the lipid profile parameters

\begin{tabular}{|c|c|c|c|c|}
\hline Parameter & & & $\begin{array}{c}\text { Camelina oil } \\
\text { Pretrial period } \\
\text { vs. } \\
\text { after intervention } \\
(n=30) \\
P \text {-value }\end{array}$ & $\begin{array}{c}\text { Canola oil } \\
\text { Pretrial period } \\
\text { vs. } \\
\text { after intervention } \\
(n=30) \\
P \text {-value }\end{array}$ \\
\hline \multirow[t]{4}{*}{ Age } & vs. & change in TC & $0.6469^{\star *}$ & $0.5072^{\star *}$ \\
\hline & vs. & change in HDL-C & $0.5852^{\star *}$ & $0.1655^{\star *}$ \\
\hline & vs. & change in LDL-C & $0.9217^{\star *}$ & $0.1543^{\star *}$ \\
\hline & vs. & change in TG & $0.5317^{*}$ & $0.1115^{\star *}$ \\
\hline \multirow[t]{4}{*}{ BMI value } & vs. & change in TC & $0.4112^{*}$ & $0.6324^{*}$ \\
\hline & vs. & change in HDL-C & $0.1577^{*}$ & $0.0670^{*}$ \\
\hline & vs. & change in LDL-C & $0.5482^{*}$ & $0.6903^{*}$ \\
\hline & vs. & change in TG & $0.5111^{*}$ & $0.6799^{*}$ \\
\hline \multirow[t]{4}{*}{ Smoking } & vs. & change in TC & $0.6942^{* * *}$ & $0.3371^{\star * *}$ \\
\hline & vs. & change in HDL-C & $0.5433^{* * *}$ & $0.7372 \bullet$ \\
\hline & vs. & change in LDL-C & $0.7871^{* * *}$ & $0.2939^{* * *}$ \\
\hline & vs. & change in TG & $0.3141 \bullet$ & $0.5598^{\star * *}$ \\
\hline
\end{tabular}

${ }^{*}$ Spearman-rank correlation, ${ }^{* *}$ Pearson correlation, ${ }^{* * *}$ Mann-Whitney $U$ test, 'Student's $t$-test for two independent groups, TC - total cholesterol, LDL-C - low-density lipoprotein cholesterol, HDL-C - high-density lipoprotein cholesterol, TG - triglycerides.

value, smoking) on the change in lipid profile parameters showed no statistically significant effect of the examined parameters $(p=0.05)$ (Table IV).

\section{Discussion}

In recent years, attention has been paid to nutraceutical products, which have a beneficial effect on reducing risk of diet-related disease, including cardiovascular disease. A lot of studies have shown that some products or substances, i.e. red yeast rice, soluble fibre, plant sterols, and unsaturated fats, may have an influence on lipid profile parameters and support treatment of dyslipidaemia [23-25]. Furthermore, nutraceuticals are also a good alternative for patients with dyslipidaemia, who cannot use statins [26]. Therefore, a study was undertaken to determine the effect of two cold-pressed oils: camelina oil rich in PUFA and canola oil rich in MUFA.

Decreasing the intake of SFA in the diet contributes to reducing serum cholesterol concentration, this reduction depends on the replacement for SFA (PUFA, MUFA, carbohydrates or a mixture of it). An additional factor affecting the lipid profile may be the dose and source of substitutes [27, 28].

In the presented study, two vegetable oils were selected: cold-pressed camelina oil rich in PUFA, with a balanced $n-3$ to n- 6 ratio, and cold-pressed canola oil rich in MUFA. The study selected the largest daily dose of oil that was well tolerated by the patient. There are other studies (regarding different vegetable oils) assessing higher daily intake, although such high doses of oil may dietary doubts.

The aim of the work was to determine how the dietary intervention influenced the all-day food rations, anthropometric parameters, blood pressure, and lipid profile.

Dietary intervention contributed to a significant reduction in SFA regardless of the oil used (a reduction of about 3\% of the energy value of the diet). Despite such a large reduction of SFA intake resulting from the diet modification of only one food product, it was not possible to reduce the percentage of energy from SFA in all-day food rations to the recommended values. Therefore, in order to decrease the percentage energy from SFA in the diet, it is necessary not only to influence PUFA and MUFA derived from visible fat, but also from fat contained in food products such as meat and meat products and confectionery.

The effect of reduced SFA intake along with diet, resulting from the intake of vegetable oils, on anthropometric parameters is not entirely clear. According to the literature, vegetable oils can influence body weight, BMI, waist and hip circumferences, and body fat mass.

The obtained results show that the dietary intervention related to the change of the fatty acid profile in the diet, while maintaining the unchanged energy value, was reflected in the waist circumfer- 
ence (approx. $1 \mathrm{~cm}$ ) in both groups of women. In addition, in the group of women consuming camelina oil, a significant decrease of WHR was observed. Interestingly, no statistically significant influence on the other parameters was observed.

Similar results were observed by other authors using various vegetable oils, i.e. coconut extra virgin oil, tea seed oil, sunflower oil [29-31], or supplementing conjugated linoleic acid [31-34]. It is worth noting, however, that some authors have also observed an effect on body weight and BMI values. Nevertheless, it could be related to the longer duration of the research. In the studies of Gillingham et al., BMI and body weight reduction were observed after consumption of canola oil and flaxseed oil; however, in the case of this study, during the intervention, the energy value of the diet changed [35].

At the moment, the cause of waist circumference reduction remains unknown. One can assume that this may be related to its laxative effect [36]. In the presented study patients reported the same effect of the test oils.

During the dietary intervention systolic and diastolic blood pressure remained unchanged. The results are similar to those of other authors [37, 38]. This suggests that the modification of the fatty acid composition of the diet does not affect the values of blood pressure in patients with normal blood pressure.

The effect of vegetable oil intake on lipid profile parameters was first studied using extra virgin olive oil. Beneficial effects from its consumption have been confirmed by numerous studies [39-41]. In recent years, oils with similar properties to olive oil that could reduce cardiovascular risk have been sought [38, 42]. There are studies suggesting the beneficial effect of oils rich in PUFA as well as rich in MUFA [27]. However, these studies often referred to one parameter influencing the development of cardiovascular diseases; for example, lipid profile, blood pressure, or anthropometric parameters. Only a few studies have analysed their impact on several parameters [30, 38, 43].

In our study, we showed that using cold-pressed oils rich in PUFA and MUFA has a positive effect on the parameters of the lipid profile. After 6 weeks of intervention a statistically significant decrease in serum total and LDL cholesterol concentration in both groups was observed. When comparing the effects of hypolipemic activity of the studied oils, camelina oil was more beneficial. Similar results were obtained in a study by Karvonen et al., in which the percentage change in LDL cholesterol in the study group of patients consuming camelina oil was $12.2 \%$ and rapeseed oil $5.4 \%$ (compared to the values obtained in our own studies: oil from camelina $-11.4 \%$ and canola oil $-8.1 \%$ ) [38].
It is worth noting that during the intervention, for some women, there was no reduction in serum total and LDL cholesterol concentration; on the contrary, an increase was observed. Similar results were observed in the Karvonen et al. study [38]. One possible explanation of this phenomenon is the pro-oxidative effect of PUFA, associated with the insufficient content of $\alpha$-tocopherol to essential unsaturated fatty acids [44].

There were no statistically significant differences in serum HDL cholesterol concentrations, which is consistent with the results of other authors [27].

The effect of dietary intervention on serum triglyceride concentration was observed only in the group of women consuming canola oil. The results were similar to Baxheinrich et al., in which, as a result of 6 months of rapeseed oil consumption, a decrease in concentrations of serum triglycerides was observed [43]. In the other studies assessing the effect of canola oil consumption on the lipid profile, there was no decrease in serum TG concentrations, although these results may have been associated with less intake of oil per day, other dosing regimens, low number of subjects, or other factors affecting the obtained results $[45,46]$.

During the dietary intervention a decrease in non-HDL cholesterol concentration in both group was observed. This change may have contributed to the reduction in the cardiovascular risk.

According to the Stein et al. study, a decrease in serum LDL cholesterol concentration cholesterol by $1 \mathrm{mmol} / \mathrm{l}(38.6 \mathrm{mg} / \mathrm{dl})$ corresponds to a $22 \%$ reduction of cardiovascular disease risk [47]. In connection with the presented dietary modification with camelina oil and canola oil, it may contribute to a reduction of cardiovascular disease risk in of the studied group of women (in our own studies, a decrease of $15 \mathrm{mg} / \mathrm{dl}(0.4 \mathrm{mmol} / \mathrm{l})$ in the group consuming camelina oil and $11 \mathrm{mg} / \mathrm{dl}$ ( $0.3 \mathrm{mmol} / \mathrm{l})$ in the group consuming canola oil).

A limitation of the present research may be the relatively short duration of the study, with a small number of patients. Further large, randomised, controlled clinical trials would provide more definitive results of whether the cold-pressed camelina oil has a beneficial effect on the lipid profile and anthropometric parameters in postmenopausal women with dyslipidaemia. However, based on this study, it can be assumed that the presented oils may support the pharmacological treatment of dyslipidaemia and in the future become an alternative medication for patients in whom statins cannot be used. In connection with the above, to improve the parameters of the lipid profile, the cold-pressed camelina oil should be included in all-day food rations, in particular to increase serum LDL cholesterol concentration. 
In conclusion, cold-pressed camelina oil and cold-pressed canola oil have a beneficial effect on the composition of all-day food rations, lipid profile parameters, and waist circumference, which play role in the prevention of cardiovascular disease and may contribute to the reduction of cardiovascular risk. Evaluating the hypolipaemic activity of test oils, it has been shown that camelina oil had better activity than canola oil.

\section{Conflict of interest}

The authors declare no conflict of interest.

\section{References}

1. Soran H, Adam S, Mohammad JB, et al. Hypercholesterolaemia - practical information for non-specialists. Arch Med Sci 2018; 14: 1-21.

2. Bai H, Sun J, Du G, Jiao F. Association of moderate aerobic exercise and rho-associated kinase 2 concentration in subjects with dyslipidemia. Arch Med Sci 2017; 13: 807-12.

3. Sao R, Aronow WS. Association of non-alcoholic fatty liver disease with cardiovascular disease and subclinical atherosclerosis. Arch Med Sci 2018; 14: 1233-44.

4. Pinkas J, Bojar I, Owoc A, Wierzbińska-Stępniak A, Raczkiewicz D. Cardiovascular diseases, metabolic syndrome and health behaviours of postmenopausal women working in agriculture. Arch Med Sci 2017; 13: 1040-8.

5. Coban N, Onat A, Guclu-Geyik F, Can G, Erginel-Unaltuna N. Sex- and obesity-specific association of aromatase (CYP19A1) gene variant with apolipoprotein B and hypertension. Arch Med Res 2015; 46: 564-71.

6. Michas G, Micha R, Zampelas A. Dietary fats and cardiovascular disease: putting together the pieces of a complicated puzzle. Atherosclerosis 2014; 234: 320-8.

7. Wenger NK. Prevention of cardiovascular disease: highlights for the clinician of the 2013 American College of Cardiology/American Heart Association guidelines. Clin Cardiol 2014; 37: 239-51.

8. Keys A, Anderson JT, Grande F. Serum cholesterol response to changes in the diet: II. The effect of cholesterol in the diet. Metabolism 1965; 14: 759-65.

9. Sprecher H, Luthria DL, Mohammed BS, Baykousheva SB. Reevaluation of the pathways for the biosynthesis of polyunsaturated fatty acids. J Lipid Res 1995; 36: 2471-7.

10. Lands WE, Morris A, Libelt B. Quantitative effects of dietary polyunsaturated fats on the composition of fatty acids in rat tissues. Lipids 1990; 25: 505-16.

11. Wood KE, Lau A, Mantzioris E, Gibsonc RA, Ramsdend $C E$, Muhlhauslerc BS. A low omega- 6 polyunsaturated fatty acid ( $n-6$ PUFA) diet increases omega-3 (n-3) long chain PUFA status in plasma phospholipids in humans. Prostaglandins Leukot Essent Fatty Acids 2014; 90: 133-8.

12. Bach A, Serra-Majem L, Carrasco JL, et al. The use of indexes evaluating the adherence to the Mediterranean diet in epidemiological studies: a review. Public Health Nutr 2006; 9: 132-46.

13. Widmer RJ, Flammer AJ, Lerman LO, Lerman A. The Mediterranean diet, its components, and cardiovascular disease. Am J Med 2015; 128: 229-38.

14. Kochhar SP. Minor and Speciality Oils. In: Vegetable Oils in Food Technology: Composition, Properties and Uses. $2^{\text {nd }}$ ed. Gunstone FD (ed.). Wiley-Blackwell, Oxford 2012; 306-9.

15. RudnikE, Szczucinska A, Gwardiak H, Szulc A, Winiarska A. Comparative studies of oxidative stability of linseed oil. Thermochim Acta 2001; 370: 135-40.

16. Ness-Abramof R, Apovian CM. Waist circumference measurement in clinical practice. Nutr Clin Pract 2008; 23: 397-404.

17. WHO. Obesity: preventing and managing the global epidemic. Report of a WHO consultation. World Health Organ Tech Rep Ser 2000; 894: 1-253.

18. Charzewska J. Instruction of the dietary recall gathering from the last 24 hours. National Food and Nutrition Institute, Warsaw 1998.

19. Szponar L, Wolnicka K, Rychlik E. Album of Photographs of Food Products and Dishes. National Food and Nutrition Institute, Warsaw 2000.

20. Kunachowicz H, Nadolna I, Przygoda B, et al. Tables of Nutritious Value of Food Products. National Food and Nutrition Institute, Warsaw 1998.

21. Nadolna I. Vitamins changes during culinary and technological processed. Nowa Med 1995; 11: 20-23.

22. Jarosz M. Nutrition standards for the population of the Polish. National Food and Nutrition Institute, Warsaw 2017.

23. Patti AM, Al-Rasadi K, Giglio RV, et al. Natural approaches in metabolic syndrome management. Arch Med Sci 2018; 14: 422-41.

24. Cicero AFG, Colletti A, Bajraktari G, et al. Lipid lowering nutraceuticals in clinical practice: position paper from an International Lipid Expert Panel. Arch Med Sci 2017; 13: $965-1005$

25. Sahebkar A, Serban MC, Gluba-Brzózka A, et al. Lipid-modifying effects of nutraceuticals: an evidencebased approach. Nutrition 2016; 32: 1179-92.

26. Banach M, Patti AM, Giglio RV, et al. The role of nutraceuticals in statin intolerant patients. J Am Coll Cardiol 2018; 72: 96-118.

27. Hooper L, Martin N, Abdelhamid A, Smith GD. Reduction in saturated fat intake for cardiovascular disease. Cochrane Database Syst Rev 2015; 10: CD011737.

28. Sacks FM, Lichtenstein AH, Wu JHY, et al. Dietary fats and cardiovascular disease: a presidential advisory from the American Heart Association. Circulation 2017; 136: e1-e23.

29. Wang J, Zhang Y, Liu Y, et al. Effects of teaseed oil on triglyceride and weight in hypertriglyceridemic subjects. Wei Sheng Yan Jiu 2014; 43: 92-5.

30. Cardoso DA, Moreira AS, de Oliveira GM, Luiz RR, Rosa G. A coconut extra virgin oil-rich diet increases HDL cholesterol and decreases waist circumference and body mass in coronary artery disease patients. Nutr Hosp 2015; 32: 2144-52.

31. Norris LE, Collene AL, Asp ML, et al. Comparison of dietary conjugated linoleic acid with safflower oil on body composition in obese postmenopausal women with type 2 diabetes mellitus. Am J Clin Nutr 2009; 90: 468-76.

32. Gaullier JM, Halse J, Høye K, et al. Supplementation with conjugated linoleic acid for 24 months is well tolerated by and reduces body fat mass in healthy, overweight humans. J Nutr 2005; 135: 778-84.

33. Gaullier JM, Halse J, Høivik HO, et al. Six months supplementation with conjugated linoleic acid induces regional-specific fat mass decreases in overweight and obese. Br J Nutr 2007; 97: 550-60.

34. Sneddon AA, Tsofliou F, Fyfe CL, et al. Effect of a conjugated linoleic acid and omega-3 fatty acid mixture on 
body composition and adiponectin. Obesity 2008; 16 : 1019-24.

35. Gillingham LG, Robinson KS, Jones PJ. Effect of high-oleic canola and flaxseed oils on energy expenditure and body composition in hypercholesterolemic subjects. Metabolism 2012; 61: 1598-605.

36. Hanif Palla A, Gilani AH. Dual effectiveness of flaxseed in constipation and diarrhea: possible mechanism. J Ethnopharmacol 2015; 169: 60-8.

37. Mutanen M, Kleemola P, Valsta LM, Mensink RP, Räsänen L. Lack of effect on blood pressure by polyunsaturated and monounsaturated fat diets. Eur J Clin Nutr 1992; 46: 1-6.

38. Karvonen HM, Antti A, Tapola NS, Salminen I, Uusitupa MI, Sarkkinen ES. Effect of alpha-linolenic acid-rich Camelina sativa oil on serum fatty acid composition and serum lipids in hypercholesterolemic subjects. Metabolism 2002; 51: 1253-60.

39. Hohmann CD, Cramer H, Michalsen A, et al. Effects of high phenolic olive oil on cardiovascular risk factors: a systematic review and meta-analysis. Phytomedicine 2015; 22: 631-40.

40. Martínez-González MA, Dominguez LJ, Delgado-Rodríguez $\mathrm{M}$. Olive oil consumption and risk of CHD and/or stroke: a meta-analysis of case-control, cohort and intervention studies. Br J Nutr 2014; 112: 248-59.

41. Carnevale R, Loffredo L, Del Ben M, et al. Extra virgin olive oil improves post-prandial glycemic and lipid profile in patients with impaired fasting glucose. Clin Nutr 2017; 36: 782-7.

42. Pan A, Yu D, Demark-Wahnefried W, Franco OH, Lin X. Meta-analysis of the effects of flaxseed interventions on blood lipids. Am J Clin Nutr 2009; 90: 288-97.

43. Baxheinrich A, Stratmann B, Lee-Barkey YH, Tschoepe D, Wahrburg U. Effects of a rapeseed oil-enriched hypoenergetic diet with a high content of $\alpha$-linolenic acid on body weight and cardiovascular risk profile in patients with the metabolic syndrome. Br J Nutr 2012; 108 682-91.

44. Witting LA. Recommended dietary allowance for vitamin E. Am J Clin Nutr 1972; 25: 257-61.

45. Iggman D, Gustafsson IB, Berglund L, Vessby B, Marckmann P, Risérus U. Replacing dairy fat with rapeseed oil causes rapid improvement of hyperlipidaemia: a randomized controlled study. J Intern Med 2011; 270: 356-64.

46. Salar A, Faghih S, Pishdad GR. Rice bran oil and canola oil improve blood lipids compared to sunflower oil in women with type 2 diabetes: a randomized, single-blind, controlled trial. J Clin Lipidol 2016; 10: 299-305.

47. Stein EA, Raal FJ. Lipid-lowering drug therapy for cardiovascular disease prevention: looking into the future. Curr Cardiol Rep 2015; 17: 104. 